\title{
Status of school feeding programme policy initiatives in primary schools in Machakos County, Kenya
}

\author{
Redempta M. Kiilu ${ }^{1 \star}$ and Lucy Mugambi ${ }^{2}$ \\ ${ }^{1}$ Department of Educational Administration and Planning, South Eastern Kenya University, P.O Box 170-90200, Kitui, \\ Kenya. \\ ${ }^{2}$ Machakos Teachers College, P.O. Box 124-90100, Machakos, Kenya.
}

Accepted 18 February, 2019

\begin{abstract}
Although education stakeholders agreed on achieving Education for All by 2015, high wastage rates in developing countries has remained a major concern. In Kenya, data shows that more than one million primary age children are still out school. In many countries, school feeding programmes has been used as one of the interventions to promote retention and improving learning outcomes in primary schools. The paper therefore investigated the status of school feeding policy initiatives in primary schools in Kenya. The objectives of the study were to examine the status of school feeding initiatives; to establish the sources of funding for feeding initiatives and assess the influence of feeding initiatives on school attendance in Machakos County. The study targeted 30 schools in Kalama and Kola zones. Simple random sampling was used to obtain a sample of 28 teachers and 55 class eight pupils while nine head teachers were selected purposively, making a total of 92 respondents. The study used descriptive survey design using questionnaires for data collection. Data was analyzed by use of descriptive statistics aided by Statistical Package for Social Sciences. Findings were presented in frequency tables and graphs. From the findings, majority of schools have implemented the primary school feeding programs as attested by $53 \%$ of the teachers, $88 \%$ of the head teachers and $61 \%$ of the pupils. However, $70 \%$ of funding for the school feeding programme come from the community and this has rendered the initiative less effective as most of the parents in the targeted schools have limited resources. The paper recommends for a more state participation to sustain the primary school feeding programme initiative in Machakos County.
\end{abstract}

Keywords: Retention, policy, safety-nets, survey, feeding programme.

*Corresponding author. E-mail: remmykyalo@gmail.com.

\section{INTRODUCTION}

Access to education is a fundamental Human Right as outlined in the 1948 Human Rights Charter. The 1990 Jomtien conference on education for all declared the need for provision of education to every person irrespective of their circumstances, whether children, the youth or adults. In fact, the Education For All second goal that emanated from the World Education Forum in Dakar urged countries to ensure that girls and children in marginalized conditions have access to free and compulsory primary education by 2015 (UNESCO, 2015). Furthermore, the Education for All (EFA) goal number five focused on achieving gender equality through full participation in quality education among girls by 2015
(UNESC0 report, 2010). Subsequently, the third of Millennium Development Goals (MDGs) focuses on ensuring that all children complete primary education of adequate quality (Republic of Kenya [RoK], 2014; RoK, 2015; UNESCO, 2010). Similarly, in the 2030 agenda for Sustainable Development, goal number four puts emphasis on access to quality inclusive education and promotion of lifelong learning opportunities for all.Infact,the plan of the first target of the fourth SDG is to ensure that all children, without discrimination based on gender complete quality free primary and secondary education by 2030 (UNESCO, 2017). Realization of the goals implies ensuring school attendance and improving 
primary school completion rates (UNESCO, 2015).

Education is a catalyst to economic growth and human development as it cures most of the societal ills, promotes employment, earnings, health and poverty reduction (The World Bank, 2018). Educational benefits spill over into social and economic realms for individuals and society as a whole. Investment in quality education is key to the attainment of almost all of the sustainable development goals by 2030 . This is due to the fact that education has been associated with improved child's well-being. Furthermore, closing the education and poverty gap spurs society's innovation and fosters social cohesion (The World Bank, 2018). Hence there is need for education systems design mechanisms to eliminate all barriers that may hinder full exploitation of individuals' capabilities.

According to classical liberal theory of equal opportunity by Horace Mann (Coombs, 1988), every individual is born with certain level of inherent capability that needs to be exploited. Ensuring that children from diverse environments complete each education cycle is vital. From research however, inequality in access to education has remained an area of concern for many countries. Although many countries have made tremendous strides towards universalization of primary education, many children are still unable to complete the relevant level of schooling as a result of extreme poverty, conflicts, disasters, HIV and AIDS affected and those discriminated on the basis of culture, religion and gender (World Bank, 2004; World Bank, 2018; UNESCO, 2017).

The 2015 EFA Global Monitoring Report points out that the children from the poorest $20 \%$ of households in poor countries are five times unlikely to complete primary school education as those from the richest $20 \%$ of households, indicating high rate of internal inefficiency. For instance, countries such as Malawi and Uganda have low pupil retention rates of only 36 percent and 56 percent up to grade six, with even lower primary school completion rates of only 16 percent and 31 percent respectively (World Bank, 2018). Current statistics globally indicates that millions of children are still deprived of of their right to education. By 2016, more than 263 million children and youth of age 16 and below were still out of school. This includes 25 million children of primary school age from low- and lower middle-income countries who will probably never set foot in a classroom (UNESCO Institute for Statistics [UIS], 2016; Human Rights Watch, 2016; World Bank, 2018). Furthermore, about 34 million girls are absent from secondary school while an estimated 24 million girls may never have the opportunity to enrol in school (Human Rights Watch, 2016). The regions with higest number (81 percent) of out of school children include sub-Saharan Africa, South and West Asia, and East Asia and the Pacific. The inability to complete the required level of education is associated with high rate of unemployment, low incomes and poor health in society (Rumberger, 2001).

The Kenya Vision 2030 overall goal is to provide a globally competitive quality education, training and research for development to reduce illiteracy, improve the transition rate from primary to secondary schools, and raise the quality and relevance of education. The Government of Kenya has therefor made a commitment to provide education that guarantees the right of every learner to quality and relevant education. The Kenya Constitution (2010) provides for basic education as a right and obligates both the state and the parents to facilitate acquisition of basic quality education by all children. The country's commitment to provision of education is reflected by the high expenditure on education. For instance, by 2010 , the expenditure on education was 12.9 percent of Gross Domestic Product, a very high level compared with other sub-Saharan countries (RoK, 2015).

In Kenya, the introduction of Free Primary Education (FPE) in 2003 led to an upsurge in pupil enrolments from 5.91000 to 7.1 pupils in 2003 and further increment in primary school enrolment from 10.1 million in 2015 to 10.3 million by 2016 (RoK, 2016). Statistics from economic survey (2017) however shows that the pupil completion rates in primary school is $83 \%$ which is less than the sustainable development goals vision for education for all children. The objectives of the Ministry of Education Strategic Plan (2008-2012) include ensuring equity in access to free and compulsory quality primary education for all to achieve 100 percent enrolment by 2015. However, retention and completion has remained a challenge as reflected in Table 1 that shows the gross enrolment rates from 2004 to 2010 .

From Table 1, net enrolment and completion rates trends indicates that participation and retention of learners in primary schools in Kenya were still below the anticipated targets. This is despite the fact that the first Medium Term Plan (MTP) for Kenya's Vision 2030 recognizes the need to have literate citizens (RoK, 2011) and the emphasis on the right to access to education for all as stipulated in The Constitution of Kenyan 2010. Some of the interventions hat has been employed in different countries to improve child retention and school attendance include structured pedagogy interventions, school feeding programs, cash transfers, improving hygiene in school infrastructure and community-based monitoring among other Multilevel interventions (The World Bank,2018).

Health and nutrition plays a vital role in child development,hence, the study study sought to examine the status of the school feeding policy initiatives in primary schools in Machakos county which has a 7.6\% illiterate population and the transition rate from primary school to secondary school is $57 \%$, far less than the expected national target of $75 \%$ by 2015 .

\section{School feeding program initiatives}

One of the interventions employed in an effort to provide 
Table 1. Gross enrolment rates (2004 - 2010).

\begin{tabular}{lccccccc}
\hline Indicator & $\mathbf{2 0 0 4}$ & $\mathbf{2 0 0 5}$ & $\mathbf{2 0 0 6}$ & $\mathbf{2 0 0 7}$ & $\mathbf{2 0 0 8}$ & $\mathbf{2 0 0 9}$ & $\mathbf{2 0 1 0}$ \\
\hline Net enrolment rate & 84.5 & 82.8 & 83.5 & 91.6 & 92.5 & 92.9 & 91.4 \\
Pupil completion rate & 78.4 & 77.6 & 76.8 & 81.0 & 79.8 & 83.2 & 76.8 \\
\hline
\end{tabular}

quality education include school feeding programmes. The objectives of school feeding programmes include improvement of school enrolment and attendance, reduction of dropout rates and low academic achievement. School feeding programs has been implemented in many countries as one of the social safety nets for child nutrition and improvement of learning and educational outcomes (Bundy et al., 2009). According to the Food and Agriculture Organization of the United Nations, an estimated 842 million people are still facing chronic hunger and are not getting enough food to lead an active and productive life (Drake et al., 2016). A survey conducted by WFP in 2008 showed that as a result of introduction of school meals, the enrolment increased from $77 \%$ in 2002 to $92 \%$ in 2007 .

Feeding of children at school setting has been associated with educational attainment and learning and this has made some countries to implement the programs to improve retention and completion rates (Bundy et al., 2009). Bundy et al. (2009) gives five quality standards to measure the effectiveness of school feeding programs and that include: Presence of a national policy framework; sufficient institutional implementation and coordination personnel; sustainable sources of funding; appropriate design for implementation. To be effective, school feeding programs need to be implemented by knowledgeable staff and stable funding. Some of the school feeding initiatives entails the provision of food to school going children, either in school for short-term hunger reduction and improvement of nutritional status for them or allowing the children to take the food rations home (Bundy et al., 2009). According to Bundy et al. (2009), in-schools food is commonly served hot to all children within the institutions and that requires planning for provision of the food, infrastructure and labor costs and this calls for community participation in planning and budgeting.

The impact of the provision of school meals cannot be under estimated. Empirical studies indicates that school feeding programmes plays a critical role in school participation (Meng and Ryan, 2003; Vermeersch and Kremer, 2004). A study conducted in Kenya by Vermeersch and Kremer (2004) showed that the provision of school meals led to increased participation among preschoolers. Similarly, the World Food Programme [WFP] (2008) posits that school Feeding Programme serves as an incentive for vulnerable families to send their children to school. This view is supported by Buttenheim et al. (2011) who associates provision of school meals with positive effects such as increased school participation and retention, improvement of child's cognitive abilities, increased attention span and reduction of vulnerability of infectious diseases that negatively affect school attendance. A study carried out by Ahmed (2004) in Bangladesh on impact of School Feeding Program showed that provision of school meals had not only enhanced learning of children butwas also attributed to high retention rates in schools in rural areas.

Similarly, a study conducted in 32 sub-Saharan countries showed a positive relationship between school feeding programmes and increase in enrolments (Gelli et al., 2007). However, He (2009) in his study Sri Lanka established that the Wolrld Food Progammes assistance had little impact on school enrolment.Consistent with this findings, Glewwe et al. (1996) observes that for school feeding initiatives to be effective, the programmes should be planned in such a manner that the benefits outweighs household income generated through child labour.

In Brazil, schools are required to purchase $30 \%$ of food from the local communities. In South Africa, over 8.8 million children from marginalized provinces get their midday meals from school (Bundy et al., 2009). In Ecuador and South Africa, structured school feeding units has clearly been established (Drake et al., 2016).

In Kenya, the rural households purchase over 76 percent of their daily food for consumption.Food security levels often drop during drought seasons and that make vulnerable families to suffer from hunger and manultrition (Republic of Kenya, 2017). To enhance child participation and perfomance in primary education,Kenya government through the Ministry of Education, Science and Technology (MoEST) developed the National School Health Policy in 2008 whose rationale is to improve learner health and nutrition (Republic of Kenya, 2015). On same note, the New Partnership for Africa Development aims to increase children direct access to food through School Feeding Programme with a target of 50 million children by 2020 (WFP, 2009). Research shows that inadequate nutritious food lead to child stunting, wastage, immune-compromise, high morbidity incidences with poor health outcomes (RoK, 2017).

From research, there is need to mobilise resources for school feeding programme. WFP (2009) points out that the programme is expensive not only for many governments but also for donors.this is supported by a study doneby the Ministry of Education (2009) who points out that the government is facing financial challenges in funding the school feedingprogrammes in Kenya arid and 
semi arid regions.

Research indicates that the implementation of the initiative increased acess and promoted retention at both pre-primary and primary school levels (RoK, 2015; RoK, 2012). Home Grown School Meals (HGSM) program carried out under the Ministry of Education, Science and Technology has seen over 1.5 million children fed at primary schools level.for instance, a study carried out by Mungai (2004) found that school feeding programmes played a major role in enhancing learning and school attendance.The debate on sustainability of the programs in terms of adequacy of supplies and organization has however remained a recurrent theme (Bundy et al., 2009). Despite the vital role played by school feeding programmes, there is dearth of information on the current status of the implementation of such policy initiative. The study set out to assess the status of school feeding initiatives in primary schools in Machakos County in Kenya.

\section{Problem of research}

As enshrined in the United Nations Convention on the Rights of the Child, education is a basic human right. The Millennium Development Goal (MDG) number two aims at ensuring that all children access free and quality education, which is also echoed in the Sustainable Development Goal (SDGs) number four. Over the last decade, many countries have made efforts to increase participation in education with commendable success. However, high dropout and low enrolment rates at all levels of education has remained an area of concern. Currently, more than one (1) million children of primary school going age are still out school (RoK, 2015; Kilu et al., 2012). In fact, Kenya ranks $9^{\text {th }}$ among countries which has the highest number of the out of school children globally (Education For All Global Monitoring Report, 2012). Statistics from economic survey (2017), the pupil completion rates in primary school is $83 \%$ which is less than the sustainable development goals vision for access to education for all children. Although existing literature indicate a positive effects of provision of meals to children in schools on school enrollments (Schultz, 2004), little has been done to establish the status of school feeding programmes in Kenya. The study was carried out to examine the status of school feeding programmes as a state policy interventions for child retention in primary schools in Machakos County, Kenya.

\section{MATERIALS AND METHODS}

The study adopted a descriptive survey design. Descriptive Survey is concerned with gathering of facts and figures that exist or existed in a population at a particular point in time and involves describing, recording, tabulating, graphing and reporting conditions rather than manipulation of variables (Fraenkel et al., 2012; Mugenda and Mugenda, 2003; Orodho, 2009). The choice of survey design was motivated by the fact that the design captures snapshots of current practices and situations and is widely used to gather standardized information using the same instruments for all participants and generates numerical data that can be summarized using descriptive statistics (Cohen et al., 2007). Survey research design is limited by its inability establish causal relationships operating within the variables (Fraenkel et al., 2012), the weakness was however overcomed by combining both quantitative and qualitative techniques to gather the relevant data.

The study targeted the head teachers, teachers and pupils in 30 public primary schools located in Kalama and Kola in Machakos sub-county. The zones were purposively selected based on the fact that they had implemented the school feeding programs and had functional guidance and counselling initiatives by 2016 .

\section{Sample of research}

The study used both probability and non-probability sampling technique to obtain the desired number of respondents. The researchers used simple random sampling to select $30 \%$ of the 30 target schools, and that prodused a sample of nine (9) public schools. The sample of $30 \%$ of the schools was deemed adequate for the purposes of generalization (Mugenda and Mugenda, 2003). To arrive at appropriate sample for teachers and students, $10 \%$ of each of the two categories of respondents was used. Through simple random sampling, 28 teachers and 55 students were obtained. Simple Random sampling was used to get students and teachers from each of the sampled schools. Simple Random sampling techniques was preferred as it ensures representativeness and also for the fact that every individual has an equal chance of being included. From the sampled schools, all the 9 head teachers and guidance and counseling teachers from the sampled schools were purposively included. Hence,the total number of respondents from the different categories were 92 participants.

\section{Instruments and procedures}

The study used both open and closed-ended questionnaires to collect quantitative and qualitative data. The authors designed a questionnaire that solicited information on status of school feeding programme policy initiatives and its influence on child retention and school attendance in primary schools in Machakos subcounty. The questionnaires were physically distributed to the 92 respondents to fill and were collected by the 
researchers after two weeks. Questionnaires were preferred due to the fact that it ensures anonymity and has the ability to collect a large quantity of data within short period of time (Fraenkel et al., 2012).

To establish validity and reliability of the research instruments, the questionnaire was piloted. Content validity was used to establish appropriateness of the content with the help of judgement from an expert in feeding progammes. The study used split-half technique to test reliability. A reliability coefficient of 0.7 was obtained and was found to be sufficienent as recommended by Mugenda and Mugenda (2003). Since the responses generated from the questionnaire depends on the willingness of the individual respondents questioned, the researchers assumed that the data generated from questionnaires indicated the current status of the implementation of school feeding programme policy initiatives in primary schools in Machakos county, Kenya.

\section{Data analysis}

Data analysis involves the application of statistical methods to the collected data in order to give meaning (Bryman, 2012). Quantitative data was cleaned up, edited and reduced appropriately to eliminate potentially incomplete or inaccurate questionnaires.Since the research involves long questionnaires and large samples of respondents, the researchers used computer coding sheets according to research questions as recommended by Gay et al. (2009). Quantitative data were analyzed by use of descriptive statistics using frequencies, means and standard deviations aided by use of Statistical Packages for social sciences (SPSS). Data gathered through semistructured interview and observation checklist will be transcribed into text format, arranged and categorized into themes. Qualitative data that emanated from semistructured responses was organized according to themes. Organization of data into themes help researchers to draw together all the relevant data for the exact area of concern, while preserving the coherence of the material (Cohen et al., 2007; Creswell, 2012).The results from data analysis were presented in tables, figures and graphs.

\section{RESULTS AND DISCUSSION}

This section presents data and discussions on the status of feeding programme in schools, status of guidance and counselling and the effectiveness of Free Primary Education on retention in primary schools in Machakos county.

The study sought to establish the status of the school feeding policy initiatives in schools in Machakos County. Head teachers, teachers and pupils were asked to indicate whether their schools have a school feeding program in place. The analyzed results of the responses are presented in Table 2.

The results in Table 2 shows that school feeding programs has been implemented in majority of the sampled schools as attested by $53 \%$ of the teachers, $88 \%$ of the head teachers and $61 \%$ of the pupils. The results shows that even though the percentage levels differ, there is consistent agreement that school feeding programme is in place in schools in Machakos subcounty. The results affirms the goverments commitment in implementation of school feeding programme as a national policy (RoK, 2017).

On the sources of funding the school feeding programme, the results are as presented in Figure 1. Regarding the sources of funding of primary school feeding programmes, all the three categories of respondents agreed that the private sector played a minimal role. However, the respondents differed on whether parents or the government player a greater role in funding. The pupils (67\%) pointed out that the parents contributed highly towards school feeding programmes, while the head teachers (65\%) and teachers $(56 \%)$ said that the government played a great role. This implies that the government is committed to implementing the policy initiative of school feeding programme.

On the aspect of whether the school feeding programme influences pupils' retention, pupils were asked to indicate whether they fail to attend school as a results of lack of provision of food in schools. The results are presented in Table 3.

The results in Table 3 shows that only $14.5 \%$ of the pupils said that they rarely attend school when there is no provision of food in school, $11 \%$ were not sure while $16 \%$ said it was very rarely. The results show that more than half of the respondents fail to attend school when there is no meals provided in schools.

The teachers and head teachers were asked to indicate the extent to which school feeding programme influences retention in primary schools. The results are as presented in Figure 2.

The results in Figure 2 shows that school feeding programme influences pupil's schools attendance and retention to a very great extent as attested by $83 \%$ of head teachers. From Figure 2, $49 \%$ of the teachers confirmed the headteachers view that the provision of food in school had high impact on child retention. This implies that when the school feeding programme is provided pupils remain in school hence minimizing dropout rates and absenteeism. This view further concurs with pupils' opinion as indicated in Table 3, where $55 \%$ of the pupils sampled indicated that they failed to attend school when there was no meals provided in their schools.

The findings from both teachers and pupils concurs with previous research carried out in Kenya by Vermeersch and Kremer (2004) which showed that the provision of school meals led to increased participation 
Table 2. Status of school feeding programmes in schools.

\begin{tabular}{lcccccccc}
\hline & \multicolumn{2}{c}{ Teachers } & & \multicolumn{2}{c}{ Head teachers } & & \multicolumn{2}{c}{ Pupils } \\
\cline { 2 - 3 } \cline { 8 - 9 } & $\mathbf{F}$ & $\%$ & & $\mathbf{F}$ & $\%$ & & $\mathbf{F}$ & $\%$ \\
\hline Yes & 15 & 53 & & 7 & 88 & & 34 & 61 \\
No & 13 & 46 & & 1 & 13 & & 21 & 38 \\
Total & 28 & 100 & & 8 & 100 & & 55 & 100 \\
\hline
\end{tabular}

Table 3. Pupil's failure to attend school due to lack of food at school.

\begin{tabular}{lcc}
\hline Frequency of absenteeism & Frequency & Percent \\
\hline Very often & 7 & 12.7 \\
Often & 25 & 45.4 \\
Not sure & 6 & 11 \\
Rarely & 8 & 14.5 \\
Very rarely & 9 & 16.3 \\
Total & 55 & 100 \\
\hline
\end{tabular}

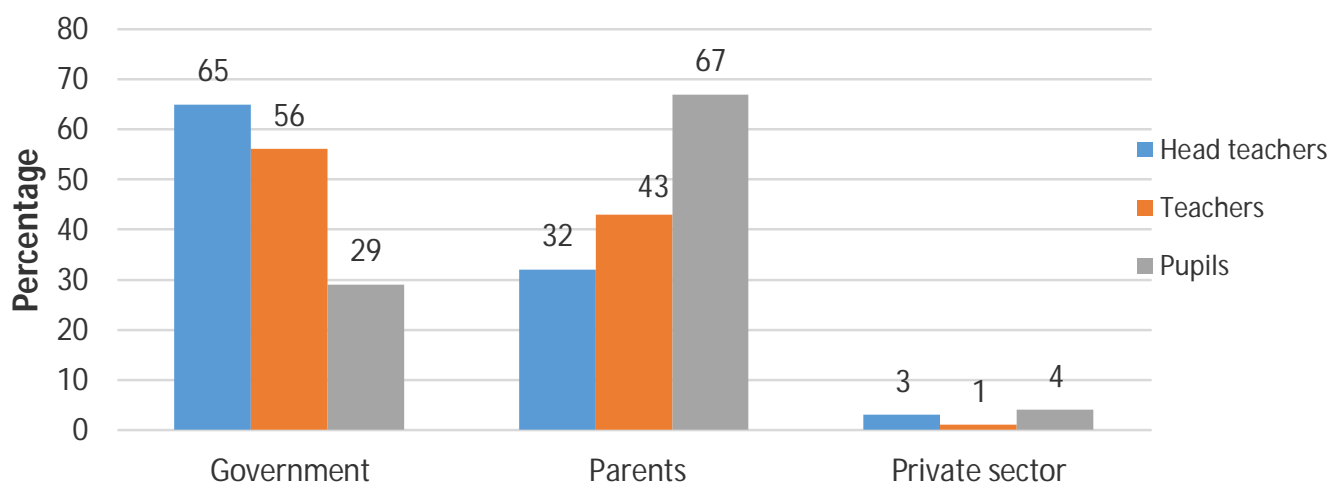

Figure 1. Sources for funding for primary school feeding programmes.

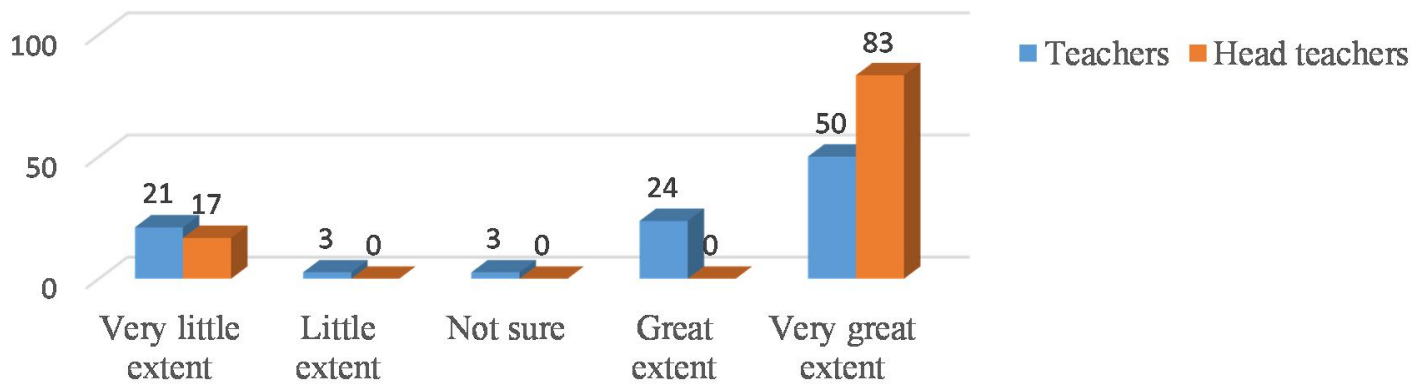

Figure 2. Teachers and head teachers' responses on influence of school feeding on school attendance.

among preschoolers. The findings are also supported by a study carried out by the World Food Programme [WFP] (2008) which found that school feeding programme served as an incentive for vulnerable families to send their children to school.

\section{CONCLUSIONS}

From the research findings, food provision in schools play a significance role in child retention. The results shows that although most schools have implemented the school 
feeding policy, parents play a vital role in funding the feeding programme, despite the fact that it was meant to cushion children from vulnerable circumstances. From the study results, feeding programme plays a vital role in child retention as attested by majority of pupils, teachers and the head teachers. The study therefore recommends for a more active state participation, together with other education stakeholders to provide food towards school feeding initiatives as it plays a vital role in sustaining children in primary schools. The study contributed knowledge regarding the status of school feeding policy initiatives in primary schools in Machakos County.

\section{REFERENCES}

Bundy, D., Burbano, C., Grosh, M., Gelli, A., Jukes, M., and Drake, L. (2009). Rethinking School Feeding: Social Safety Nets, Child Development, and the Education Sector. The World Bank.

Buttenheim, A. M., Alderman, H., and Friedman, J. A. (2011). Impact Evaluation of School Feeding Programs in Lao PDR, 2011, World Bank Policy Research Working Paper Series, 5518.

Cohen, L., Manion, L., and Morrison, K. (2007). Research Methods in education (6th edition). London: Routledge.

Coombs, P. (1988). The world Crisis in Education. New York: Oxford University Press.

Drake, L., Woolnough, A., Burbano, C., and Bundy, D. (2016). Global School Feeding Sourcebook Lessons from 14 countries. Imperial College Press, London.

Fraenkel, J. R., Wallen, N. E., and Hyun, H. H. (2012). How to Design and Evaluate Research in Education (8th edition). McGraw Hill, New York, USA.

Gay, L. R., Mills, G. E., and Airasian, P. (2009). Educational Research Competencies for Analysis and Applications (9th Edition). Pearson International.

Gelli, A., Meir, U., and Espejo, F. (2007). Does provision of food in school increase girls' enrolment? Evidence from schools in subSaharan Africa. Food and Nutrition Bulletin, 28(2): 149-155.

Glewwe P., Jacoby, A., and King, E. (1996). An Economic Model of Nutrition and Learning: Evidence from Longitudinal Data. World Bank Policy Research Department: Washington, D.C.

He, F. (2009). School Feeding Programs and Enrollment: Evidence from Sri Lanka.

Human Rights Watch (2016). The Education Deficit: Failures to Protect and Fulfil the Right to Education in Global Development Agendas.

Kiilu, R., Mulwa, and Muasau (2012). Critical Analysis of the effectiveness of Programmes and activities Developed by MoE to Improve Educational Access, Quality and Equity.

Meng, X., and Ryan, J. (2003). Evaluating the Food for Education Program in Bangladesh.

Mugenda, O. M., and Mugenda, A. G. (2003). Research Methods: Quantitative and Qualitative Approaches. African Centre for Technology Studies; Nairobi, Kenya.

Orodho, A. (2009). Techniques of writing research proposals and reports in Education and Social Sciences Kanezja Enterprises.

Republic of Kenya (ROK) (2011). Second Annual Progress Report on the Implementation of the First Medium Term Plan (2008-2012) of Kenya Vision 2030.

Republic of Kenya (ROK) (2012). Sessional Paper No. 14 of 2012: Reforming Education and Training Sectors in Kenya. Nairobi: Government Printer.
Republic of Kenya (ROK) (2014). Education For All the 2015 National Review. Kenya.

Republic of Kenya (ROK) (2015). Education for All 2015 National Review Report: Kenya.

Republic of Kenya (ROK) (2016). Kenya National Bureau of Statistics.

Republic of Kenya (ROK) (2017). Implemementation of The Agenda 2030 For Sustainable Development in Kenya.

Rumberger, W. R. (2001). Who Drops Out of School and Why? Paper prepared for the National Research Council, Committee on Educational Excellence and Testing Equity Workshop. Washington DC.

UNESCO (2010). UNESCO National Education Support Strategy (UNESS) for the Republic of Kenya (2010 - 2011).

UNESCO (2017). Education for Sustainable Development Goals.

World Bank (2004). Natural Disasters: Eluding Nature's Wrath' (mimeo). World Bank, Washington, D.C.
Citation: Kiilu, R. M., and Mugambi, L. (2019). Status of school feeding programme policy initiatives in primary schools in Machakos County, Kenya. African Educational Research Journal, 7(1): 33-39 